\title{
PENGARUH MOTIVASI DAN KEPUASAN KERJA TERHADAP KINERJA TUTOR DI UPBJJ TARAKAN DITINJAU DARI FAKTOR PENGHASILAN, KEAMANAN KERJA, KONDISI KERJA DAN FASILITAS
}

\section{THE EFFECT OF MOTIVATION AND JOB SATISFACTION ON TUTOR PERFORMANCE IN UPBJJ TARAKAN REVIEWED FROM INCOME FACTORS, WORK SAFETY, WORKING CONDITIONS AND FACILITI}

\author{
Andre Suandi Simbolon ${ }^{1}$ Anton Robiansyah ${ }^{2,}$ Andi Lopa Ginting ${ }^{3}$ Steviani \\ Batti $^{1}$ \\ ${ }^{\mathbf{1}}$ Program Studi Manajemen, Fakultas Ekonomi, Universitas Terbuka \\ ${ }^{2}$ Program Studi Akuntansi, Fakultas Ekonomi, Universitas Terbuka \\ ${ }^{3}$ Program Studi Ekonomi Pembangunan, Fakultas Ekonomi, Universitas Terbuka \\ andre.simbolon@ecampus.ut.ac.id
}

Abstrak: Tutorial merupakan salah satu bentuk layanan akademik Universitas Terbuka untuk membantu mahasiswa dalam proses belajarnya. Kinerja tutor mencerminkan rasa tanggung jawab dalam menyelenggarakan tugas yang diberikan, yang tentunya akan mendorong gairah kerja, semangat kerja, dan motivasi kerja serta kepuasan kerja. Pengumpulan data melalui metode observasi, wawancara dan penyebaran kuesioner kepada responden yang berupa google form dan pertanyaan secara tertulis untuk mendapatkan data untuk diproses. Sehingga sumber data dalam penelitian ini merupakan data primer yang diperoleh secara langsung dari objek penelitian. Teknik analisis yang digunakan adalah Partial Least Square (PLS). Hasil penelitian menunjukkan bahwa secara signifikan yang berpengaruh terhadap kinerja tutor adalah kepuasan kerja.

Kata kunci: Motivasi, Kepuasan Kerja, Kinerja Tutor

Abstract: Tutorials are a form of Open University academic services to assist students in their learning process. The tutor's performance reflects a sense of responsibility in carrying out the assigned task, which of course will encourage work enthusiasm, work morale, and work motivation and job satisfaction. Collecting data through the method of observation, interviews and distributing questionnaires to respondents in the form of google forms and questions in writing to obtain data for processing. So that the data source in this study is primary data which is obtained directly from the object of research. The analysis 
technique used is Partial Least Square (PLS). The results showed that job satisfaction has a significant effect on tutor performance.

Keywords: Motivation, Job Satisfaction, Tutor Performance

\section{PENDAHULUAN}

Unit Program Belajar Jarak Jauh Universitas Terbuka Tarakan (UPBJJ UT Tarakan) merupakan salah satu cabang Unit Program Belajar Jarak Jauh Universitas Terbuka (UPBJJ-UT) yang menyediakan sistem pembelajaran jarak jauh. Tujuan dibukanya UPBJJUT Tarakan sebagai komitmen dan pengabdian Univeristas Terbuka untuk terus meningkatkan pelayanan dan mendobrak keterbatasan masyarakat dalam memperoleh kesempatan serta kemudahan akses pendidikan kepada mahasiswa dan masyarakat yang sibuk dan tidak memiliki waktu karena pekerjaan atau alasan lainnya, sehingga seluruh mahasiswa yang berada di wilayah Kalimantan Utara mendapatkan layanan pembelajaran dengan lebih mudah.

Program penyelenggaraan belajar jarak jauh Universitas Terbuka menuntut mahasiswa untuk dapat belajar secara mandiri, pembelajaran mandiri menuntut mahasiswa untuk mempelajari bahan ajar sendiri, baik cetak ataupun non cetak, dan mengerjakan tugas sendiri. Namun karena kebiasaan dalam menjalankan pendidikan sebelumnya seperti di SD, SMP dan
SMA yang bergantung pada informasi yang langsung disampaikan oleh pengajar, sebagian besar mahasiswa Universitas Terbuka belum mampu belajar secara mandiri sehingga banyak diantara mereka mengalami masalah dalam belajar, maka untuk mengatasi masalah ini salah satu cara yang dilakukan Universitas Terbuka adalah melalui pola pembelajaran tutorial. Hal ini didukung oleh pernyataan dari Wardani (2000), bahwa mahasiswa yang belajar pada pendidikan jarak jauh, masih memerlukan bantuan akademik dalam bentuk layanan tutorial. Tutorial merupakan salah satu bentuk layanan akademik Universitas Terbuka untuk membantu mahasiswa dalam proses belajarnya.

Berbagai program menyangkut penyelenggaraan kegiatan tutorial, seperti diterapkannya tutorial tatap muka, tutorial elektronik, tutorial tertulis, dan program tutorial tatap muka rancangan khusus (TTMRK) merupakan upaya untuk membantu mahasiswa mencapai hasil belajar yang optimal.

Tutorial merupakan salah satu bentuk layanan bantuan belajar yang diberikan kepada mahasiswa untuk membantu mahasiswa mencapai hasil belajar secara optimal (Sugiran, 
Daulay, dkk, 2016). Tutor dalam menjalankan tugasnya tidaklah jauh berbeda dengan pendidik lainnya, yaitu memberikan pendidikan, pengajaran, membimbing, mengarahkan, melatih, menilai, dan mengevaluasi peserta didik. Tugas tutor jauh lebih berat, yaitu: harus menyiapkan bahan-bahan yang sesuai untuk diajarkan, menguasai materi, mampu menjelaskan konsepkonsep materi, mampu berkomunikasi dengan mahasiswa, dan mampu membuat penilaian (progress) mahasiswa (Arends, 2011). Kinerja tutor mencerminkan rasa tanggung jawab dalam menyelenggarakan tugas yang diberikan, yang tentunya akan mendorong gairah kerja, semangat kerja, dan motivasi kerja serta kepuasan kerja. Proses belajar mengajar akan berlangsung dengan baik apabilah didukung dengan tutor yang mempunyai motivasi dan kepuasan kerja yang tinggi.

Menurut Handoko (2008), seseorang bekerja dengan produktif atau tidak tergantung pada motivasi, kepuasan kerja, tingkat stres, kondisi fisik pekerjaan, sistem kompensasi, desain pekerjaan dan aspek-aspek lainnya. Tutor yang termotivasi dan memiliki kepuasan kerja yang tinggi akan menghasilkan kinerja yang baik pula.

10 faktor-faktor motivasi kerja menurut Yunus (2007), yaitu: (1) rasa aman, (2) kesempatan untuk maju, (3) tipe pekerjaan, (4) nama baik tempat kerja, (5) rekan kerja, (6) penghasilan, (7) supervisor, (8) jam kerja, (9) kondisi kerja, dan (10) fasilitas.

Moh. Assead, (2003), menyatakan bahwa menurut Blum ada 10 faktor-faktor kepuasan kerja, yaitu (1) kesempatan untuk maju, (2) keamanan kerja, (3) gaji, (4) perusahaan dan managemen, (5) pengawasan, (6) faktor intrinsik dari kerjaan, (7) kondisi kerja, (8) aspek sosial dalam pekerjaan, komunikasi dan (10) fasilitas. Artinya, untuk memaksimalkan motivasi dan kepuasan kerja tutor harus didukung dari masing-masing 10 faktor-faktor tersebut.

Kinerja tutor menjadi masalah tersendiri, karena faktor status yang melekat padanya sebagai mitra Universitas Terbuka yang terdiri dari Dosen atau Ahli di luar kepegawaian Universitas Terbuka sehingga gaji atau pendapatan yang dimiliki selama ini jauh dari cukup. Dengan kata lain, insentif atau gaji yang mereka terima mungkin tidak sebanding dengan pekerjaan yang mereka laksanakan, begitu juga ketika harus melakukan tutorial tatap muka (TTM) membutuhkan kehadiran seorang tutor untuk bertatap muka dengan mahasiswa yang berada di daerah-daerah terpencil dan tanggung jawab yang mereka terima terhadap masa depan mahasiswa Universitas Terbuka, berhasil atau tidaknya menyelesaikan 
program pendidikan yang sudah diprogramkan.

\section{TINJAUAN PUSTAKA}

\section{Kinerja Tutor}

Kinerja merupakan hasil kerja secara kualitas dan kuantitas yang dicapai oleh seorang dalam melaksanakan fungsinya sesuai dengan tanggung jawab yang diberikan kepadanya. Kinerja sebagai hasil-hasil fungsi pekerjaan/kegiatan seseorang atau kelompok dalam suatu organisasi yang dipengaruhi oleh berbagai faktor untuk mencapai tujuan organisasi dalam periode waktu tertentu. Robbins (2009) menyatakan pengertian kinerja mengarah pada suatu upaya pencapaian prestasi kerja yang lebih baik. Senada dengan yang dikatakan (Wirawan, 2009), kinerja adalah keluaran yang dihasilkan oleh fungsi-fungsi atau indikator-indikator suatu pekerjaan atau suatu profesi dalam waktu tertentu.

Sedangkan tutor secara umum merupakan suatu profesi, dengan demikian tutor dengan kinerjanya adalah menyangkut seluruh aktivitas yang ditunjukkan oleh pendidik dalam tanggung jawabnya sebagai orang yang mengemban suatu amanat dan tanggung jawab untuk mendidik, mengajar, membimbing, mengarahkan, dan memandu peserta didik dalam rangka menggiring perkembangan peserta didik ke arah kedewasaan mental spritual maupun fisik biologis.

Yamin dan Maisah (2010), kinerja pendidik atau tutor adalah perilaku atau respon yang memberi hasil yang mengacu kepada apa yang mereka kerjakan ketika dia menghadapai suatu tugas. Kinerja tutor menyangkut semua kegiatan atau tingkah laku yang dialami tutor, jawaban yang tutor berikan, untuk memberi hasil atau tujuan.

Pengukuran kinerja tutor dilakukan dengan melihat jumlah output yang dihasilkan oleh setiap tutor. Kinerja pendidik atau tutor adalah suatu konsep yang menunjukkan adanya kaitan output dengan input yang dibutuhkan seorang tenaga kerja untuk menghasilkan produk (Robert dan John, 2006).

Dapat disimpulkan bahwa kinerja tutor adalah suatu bentuk hasil kerja atau hasil usaha berupa tampilan fisik, maupun gagasan yang sering dihubungkan dengan kompetensi pada diri tutor tersebut.

Handoko (2008) menyatakan ada beberapa faktor yang memengaruhi kinerja seseorang. Seseorang bekerja dengan produktif atau tidak tergantung pada:

\section{Motivasi}

Dalam hubungannya dengan kinerja organisasi, semakin besar motivasi kerja karyawan semakin tinggi kinerjanya.

2. Kepuasan Kerja 
Kepuasan kerja merupakan faktor yang diyakini dapat mendorong dan memengaruhi semangat kerja seseorang agar seseorang dapat bekerja dengan baik dan secara langsung akan memengaruhi kinerja seseorang.

3. Stres Kerja

Stres kerja yang dialami oleh seseorang tentunya akan merugikan organisasi yang bersangkutan karena kinerja yang dihasilkan akan menurun, tingkat absensi tinggi dan turnover yang tinggi.

4. Kondisi Fisik Pekerjaan

Kondisi fisik tempat kerja yang aman dan sehat diperlukan oleh setiap pegawai.

5. Sistem Kompensasi

Pemberian kompensasi dalam suatu organisasi harus diatur sedemikian rupa sehingga merupakan sistem yang baik dalam organisasi.

6. Desain Pekerjaan

Ada banyak upaya diarahkan untuk konsep dan mengukur struktur desain pekerjaan.

\section{Kepuasan Kerja}

Kepuasan kerja tutor merupakan keadaan emosional yang dialami tutor karena keterkaitannya dengan tugas dan kewajibannya sebagai tenaga pendidik di suatu instansi. Robbins (2008) mendefinisikan kepuasan kerja adalah suatu sikap umum seorang individu dan banyaknya yang mereka yakini seharusnya mereka terima.

Selain itu kepuasan kerja juga dapat diartikan sebagai sebuah efektivitas atau respon emosional terhadap berbagai aspek pekerjaan (Kreitner, 2005). Lebih jauh dikatakan bahwa kepuasan kerja mencerminkan perasaan seseorang terhadap pekerjaannya, yang dapat terlihat dari sikap positif pekerja terhadap pekerjaannya dan segala sesuatu yang dihadapi pada lingkungan kerja.

Indikator kepuasan kerja menurut Celluci dan David (1978) yaitu:

1. Kepuasan terhadap gaji.

Kepuasan gaji yang diperoleh oleh seseorang haruslah sebanding dengan usaha yang dilakukan dan sama dengan upah yang diterima oleh orang lain dalam posisi yang sama.

2. Kepuasan terhadap promosi.

Kesempatan seseorang untuk meraih atau dipromosikan ke jenjang yang lebih tinggi dalam suatu organisasi.

3. Kepuasan terhadap rekan kerja. Sejauh mana rekan kerja secara teknis cakap dan secara sosial mendukung tugas rekan kerja lainnya.

4. Kepuasan terhadap pekerjaan itu sendiri.

Sejauh mana pekerjaan menyediakan kesempatan seseorang untuk memperoleh tanggungjawab dalam suatu 
tugas tertentu dan tantangan untuk pekerjaan yang menarik.

5. Kepuasan terhadap supervisor. Atasan memberikan bantuan teknis dan dukungan terhadap pekerjaan yang menjadi tanggungjawab para bawahan.

Menurut Blum (dalam Moh. Aseead, 2003) faktor-faktor yang mempengaruhi kepuasan kerja adalah:

1. Kesempatan untuk maju.

Dalam hal ini ada tidaknya kesempatan untuk memperoleh pengalaman dan peningkatan kemampuan selama kerja.

2. Keamanan kerja.

Keamanan kerja sebagai penunjang kepuasan kerja, baik bagi karyawan pria maupun wanita.

3. Gaji

Gaji lebih banyak menyebabkan ketidakpuasan, dan jarang orang mengekspresikan kepuasan kerjanya dengan sejumlah uang yang diperolehnya.

4. Perusahaan dan Manajemen

Perusahaan dan manajemen yang baik adalah yang mampu memberikan situasi dan kondisi kerja yang stabil.

5. Pengawasan

Bagi karyawan, supervisor dianggap sebagai figur ayah dan sekaligus atasanya.

6. Faktor intrinsik dari pekerjaan

Sukar dan mudahnya serta kebanggaan akan tugas akan meningkatkan atau mengurangi kepuasan.

7. Kondisi kerja

Termasuk di sini adalah kondisi tempat, ventilasi, penyinaran, kantin dan tempat parkir.

8. Aspek sosial dalam pekerjaan Merupakan salah satu sikap yang sulit digambarkan tetapi dipandang sebagai faktor yang menunjang puas atau tidak puas dalam kerja.

9. Komunikasi

Komunikasi yang lancar antara karyawan dengan pihak manajemen banyak dipakai alasan untuk menyukai jabatannya.

10. Fasilitas

Fasilitas rumah sakit, cuti, dana pensiun atau perumahan merupakan standar suatu jabatan dan apabila dapat dipenuhi akan menimbulkan rasa puas.

\section{Motivasi Kerja}

Motivasi kerja merupakan gairah seseorang yang dengan senang hati mengerahkan kemampuan dalam bentuk keahlian atau keterampilan tenaga dan waktunya untuk melakukan berbagai kegiatan yang menjadi tanggung jawabnya serta melaksanakan kewajibannya dalam angka pencapaian tujuan dan berbagai sasaran organisasi yang telah ditentukan. Mathis dan Jackson (2006) mendefinisikan motivasi sebagai hasrat di dalam diri 
seseorang yang menyebabkan orang tersebut melakukan suatu tindakan.

Robbins (2006) berpendapat bahwa motivasi kerja diukur dalam dua dimensi, yaitu motivasi eksternal yang meliputi hubungan antarpribadi, penggajian, supervisi kepala sekolah dan kondisi kerja dan motivasi internal meliputi dorongan untuk bekerja, kemajuan dalam karier, pengakuan yang diperoleh, rasa tanggung jawab dalam pekerjaan, minat terhadap tugas dan dorongan untuk berprestasi.

Berdasarkan berbagai teori mengenai motivasi kerja tersebut, maka konsep yang mendorong atau memotivasi kerja adalah sebagai berikut:

1. Kebutuhan mempertahankan hidup, yaitu kebutuhan yang berupa makan, minum, perumahan, udara, dan sebagainya.

2. Kebutuhan rasa aman, yaitu terjaminnya rasa aman bagi guru yang menyangkut keamanan akan jiwa, harta dan terbebas dari rasa waswas/ takut serta adanya perlakuan yang adil.

3. Kebutuhan sosial, terlihat dalam kebutuhan akan perasaan diterima dan merasa diasingkan dari habitate sosialnya serta adanya pengakuan atas harkat dan martabatnya di hadapan masyarakat serta pengakuan dari habitat sosialnya.
4. Kebutuhan akan penghargaan, kebutuhan ini nampak dalam status sosial yang dimiliki oleh warga masyarakat, seperti kondisi sosial ekonominya, bentuk rumah yang bermodel paling baru, kendaraan yang dimiliki, yang pada akhirnya memperoleh pengakuan / penghargaan warga.

5. Kebutuhan dalam mengaktualisasikan diri, berupa kebutuhan untuk mengaktualisasikan atau mewujudkan kemampuan dan potensi dirinya ke dalam bentuk kiprah nyata dalam kegiatan-kegiatan sekolah.

Menurut David C. Mc.Clelland dalam Steers dan Braunstein (1976), menyebutkan bahwa indikator motivasi adalah sebagai berikut :

1. Kebutuhan untuk berprestasi (need for achievement)

Kebutuhan untuk berprestasi merupakan daya penggerak yang memotivasi semangat kerja seseorang.

2. Kebutuhan berafiliasi (need for affiliation)

Keinginan untuk memiliki kebutuhan bersosialisasi dan interaksi dengan mengarahkan tingkah laku untuk mengadakan hubungan dengan orang lain.

3. Kebutuhan kekuatan (need for power)

Mengarahkan semua kemampuan demi mencapai kekuasaan atau kedudukan yang terbaik di dalam 
organisasi yang menimbulkan persaingan secara sehat oleh atasan agar bawahannya termotivasi untuk bekerja lebih giat.

\section{METODOLOGI PENELITIAN}

Rancangan penelitian ini bersifat explanatory dalam bentuk survey yang bertujuan untuk menjelaskan fenomena yang ada dan mencari keterangan-keterangan secara faktual.

Penelitian ini mengambil tempat di Universitas Terbuka UPBJJ Kota Tarakan Kalimantan Utara dengan ruang lingkup penelitian dibatasi pada motivasi, kepuasan kerja dan kinerja tutor UPBJJ Tarakan.

Populasi dalam penelitian ini adalah seluruh tutor yang terdata di database UPBJJ Tarakan dengan sample sejumlah 200 orang responden. Sampel diambil dengan menggunakan teknik simple random sampling, karena populasi dianggap mempunyai probability yang sama untuk menjadi sampel dalam penelitian ini. Setelah penetapan sampel, dilanjutkan dengan pengumpulan data melalui metode observasi, wawancara dan penyebaran kuesioner kepada responden yang berupa google form dan pertanyaan secara tertulis untuk mendapatkan data untuk diproses. Sehingga sumber data dalam penelitian ini merupakan data primer yang diperoleh secara langsung dari objek penelitian.

Analisis data yang digunakan adalah analisis deskriptif berfungsi untuk mendeskripsikan atau memberi gambaran terhadap obyek yang diteliti serta untuk mengetahui karakteristik serta tanggapan responden terhadap item-item pertanyaan pada kuesioner. Teknik analisis yang digunakan adalah Partial Least Square (PLS) dalam Ghozali (2009) yaitu untuk tujuan memprediksi terutama pada kondisi dimana indikator bersifat formatif. Di dalam PLS model structural hubungan antar variabel laten disebut dengan inner model, sedangkan model pengukuran (bersifat refleksif atau formatif) disebut outer model..

\section{HASIL DAN PEMBAHASAN}

Responden dalam penelitian ini adalah Tutor pada Universitas Terbuka UPBJJ Kota Tarakan. Karakteristik responden terdiri dari $69.243 \%$ pria dan $30.77 \%$ wanita. Dengan rentang umur responden terendah 26 tahun dan tertinggi 60 Tahun. Deskripsi data yang disajikan dalam bagian ini meliputi data variabel: motivas (X1), kepuasan kerja (X2), dan kinerja tutor (Y). Seperti telah diuraikan dalam bagian sebelumnya, penelitian ini bersifat kausal yang mengkaji kompleksitas hubungan antara variabel-variabel yang diteliti, dimana jenis variabel yang digunakan adalah variabel laten 
endogenous (variabel terikat) dan variabel laten exogenous (variabel bebas).

Dalam penelitian ini, variabel laten endogenous adalah kinerja tutor (Y), sedangkan variabel laten exogenous-nya adalah motivasi (X1) dan kepuasan kerja (X2). Semua variabel laten pada penelitian ini menggunakan tipe indikator refleksif (arah panah dari variabel laten menuju ke indikator). Pada penelitian ini dapat dikontraksi diagram jalur dengan menggunakan batuan software Smart PLS versi 3.

\section{Uji Validitas Model}

Ukuran individual dikatakan valid jika memiliki korelasi (loading) dengan konstruk (variabel laten) yang ingin diukur $\geq 0.5$ atau nilai $\mathrm{T}$ statistiknya harus $\geq 1.96$ (uji dua pihak) pada level signifikansi 0.05 . Jika salah satu indikator memiliki nilai loading $<0.5$ atau T-statistik < 1.96, maka indikator tersebut harus dibuang (didrop) karena mengindikasikan bahwa indikator tidak cukup baik untuk mengukur konstruk secara tepat. Berdasarkan seluruh hasil pengujian validitas pada tabel 1 di atas diketahui bahwa semua indikator telah signifikan secara statistik dan valid dalam mengukur masing - masing indikatornya. Sehingga tidak ada indikator yang dieliminasi dalam analisis lebih lanjut. Indikator yang memiliki sumbangan efektif terbesar pada setiap indikator dapat diketahui dengan melihat sampel mean yang diperoleh dari hasil bootstrap pada Smart PLS. Indikator yang memiliki sumbangan efektif terbesar terhadap variabel laten motivasi adalah indikator rasa aman (X1.2) dengan nilai 0.836 . Sedangkan pada variabel laten kepuasan kerja memiliki sumbangan efektif terbesar pada indikator Gaji (X2.1) sebesar 0.778. Dan pada variabel laten kinerja tutor, indikator yang memiliki sumbangan efektif terbesar adalah indikator ketepatan waktu (Y1.1) sebesar 0.796 .

Tabel 1 Uji Validitas Indikator

\begin{tabular}{cccccc}
\hline \multirow{2}{*}{ Konstruk } & Indikator & $\begin{array}{c}\text { Original } \\
\text { Sample }\end{array}$ & $\begin{array}{c}\text { Sample } \\
\text { Mean }\end{array}$ & $\rho$-Value & Keterangan \\
\hline \multirow{4}{*}{ Motivasi } & X1.1 & 0.705 & 0.701 & 0.000 & Valid \\
& X1.2 & 0.836 & 0.831 & 0.000 & Valid \\
& X1.3 & 0.628 & 0.633 & 0.000 & Valid \\
& X1.4 & 0.542 & 0.533 & 0.000 & Valid \\
\hline \multirow{5}{*}{ Kepuasan Kerja } & X2.1 & 0.778 & 0.776 & 0.000 & Valid \\
& X2.2 & 0.746 & 0.743 & 0.000 & Valid \\
& X2.3 & 0.746 & 0.743 & 0.000 & Valid \\
& X2.4 & 0.609 & 0.585 & 0.000 & Valid \\
\hline \multirow{3}{*}{ Kinerja Tutor } & Y1.1 & 0.796 & 0.801 & 0.000 & Valid \\
& Y1.2 & 0.682 & 0.677 & 0.000 & Valid \\
& Y1.3 & 0.733 & 0.72 & 0.000 & Valid \\
\hline
\end{tabular}




\section{Uji Reliabilitas Model}

Pada penelitian ini, uji reliabilitas menggunakan composite reliability, yang disajikan pada tabel 2:

\section{Tabel 2 Uji Reliabilitas Komposit} Reliabilitas

\begin{tabular}{lll} 
Konstruk & Komposit & Keterangan \\
\hline $\begin{array}{l}\text { Motivasi } \\
\text { Kepuasan }\end{array}$ & 0.813 & Realibel \\
Kerja & 0.782 & Realibel \\
Kinerja Tutor & 0.777 & Realibel \\
\hline
\end{tabular}

Berdasarkan tabel 2, hasil uji reliabilitas komposit untuk variabel laten motivasi dijelaskan oleh empat indikator yaitu kebutuhan mempertahankan hidup, kebutuhan rasa aman, kebutuhan sosial, dan kebutuhan akan penghargaan memiliki $\rho$ c sebesar 0.813 . Sedangkan variabel kepuasan kerja yang juga terdiri dari empat indikator yaitu kepuasan terhadap gaji, kepuasan terhadap promosi, kepuasan terhadap rekan kerja, dan kepuasan terhadap pekerjaan itu sendiri memiliki $\rho c$ sebesar 0.782 .

Dan terakhir variabel laten kinerja tutor yang memiliki indikator ketepatan waktu, kuantitas pekerjaan, dan kualitas pekerjaan memiliki $\rho c>$ 0.777. Berarti dari hasil di atas dapat disimpulkan bahwa seluruh indikator-indikator yang digunakan dapat dipercaya untuk mengukur konstruknya.

Uji Kelayakan Model (goodness of fit)
Dari inner model diketahui terdapat satu variabel terikat yaitu kinerja tutor, dan dua variabel bebas yaitu motivasi dan kepuasan kerja. Dari output PLS diperoleh harga koefisien determinasi untuk variabel terikat seperti disajikan pada tabel 3:

Tabel 3 Hasil R-square

\begin{tabular}{lr}
\hline Konstruk & R Square \\
\hline Kinerja Tutor & 0.620 \\
\hline
\end{tabular}

Hasil pengujian inner model dapat terlihat hubungan antar konstruk dengan dengan cara membandingkan nilai signifikansi dan R-square dari model penelitian (Ghozali, 2009:42). Hasil pengolahan data nilai R-square variabel kinerja tutor sebesar 0.620 , dapat diintepretasikan bahwa $62 \%$ variabilitas kinerja dapat dijelaskan oleh variance motivasi dan kepuasan kerja, sedangkan sisanya sebesar $38 \%$ dijelaskan oleh variabel lain di luar model.

\section{Uji Signifikansi Jalur}

Berdasarkan hasil estimasi bootstrap dengan menggunakan jumlah sampel sebanyak 200responden.

Uji signifikansi jalur diperoleh pada gambar 1 dengan nilai koefisien parameter untuk model struktural (inner model) yaitu pengaruh motivasi terhadap kinerja tutor dengan nilai t-statistik sebesar 5.707 $>$ 1.96. Sedangkan kepuasan kerja 
terhadap kinerja tutor dengan nilai tstatistik sebesar $1.782<1.96$. Dari hasil ini dapat kita simpulkan bahwa hanya motivasi kerja yang berpengaruh terhadap kinerja tutor, sedangkan kepuasan kerja memiliki pengaruh yang tidak signifikan

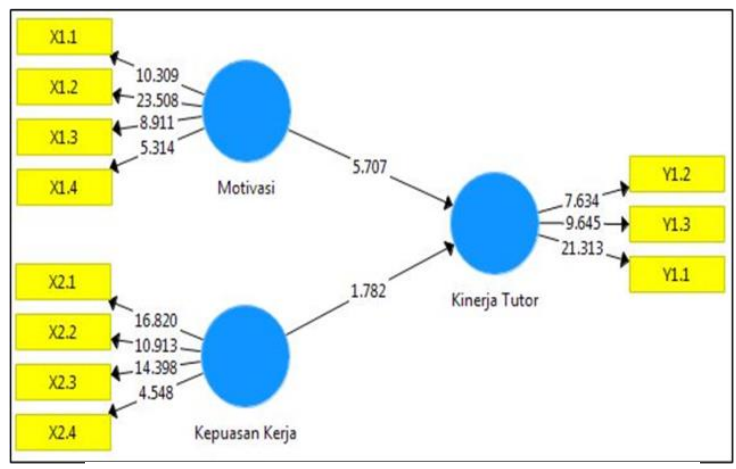

Gambar 1 Model Signifikansi

\section{Pengujian Hipotesis}

Nilai yang terdapat pada output result for inner weight merupakan dasar yang digunakan dalam menguji hipotesis penelitian. Pengujian hipotesis tentang koefisien jalur atau pengaruh motivasi terhadap kinerja tutor dan pengaruh kepuasan kerja terhadap kinerja tutor di sajikan pada tabel 4.

Pada pengujian ini dilakukan uji hipotesis pada analisis PLS, pada dasarnya untuk mengetahui pengaruh motivasi dan kepuasan kerja terhadap kinerja tutor.
Uji statistik yang digunakan adalah uji t.

1. Motivasi terhadap kinerja tutor

$$
\begin{aligned}
& \mathrm{H} 0: \beta y 1 \leq 0 \\
& \mathrm{H} 1: \beta y 1>0
\end{aligned}
$$

Berdasarkan hasil analisis data dengan menggunakan aplikasi SmartPLS Versi 3, diperoleh koefisien jalur $(\gamma 1)=0.619$

Harga $\mathrm{t}$ hitung $=5.476$, sedangkan harga $t$ tabel $=1.96$. Fakta ini mengungkapkan bahwa thitung > t tabel, berarti H0 ditolak dan $\mathrm{H} 1$ diterima. Artinya koefisien jalur ini sangat signifikan.

2. Kepuasan kerja terhadap kinerja tutor

$$
\begin{aligned}
& \mathrm{H} 0: \beta y 1 \leq 0 \\
& \mathrm{H} 1: \beta y 1>0
\end{aligned}
$$

Berdasarkan hasil analisis data dengan menggunakan aplikasi SmartPLS Versi 3, diperoleh koefisien jalur $(\gamma 1)=0.202$. Harga $t$ hitung $=1.715$, sedangkan harga $\mathrm{t}$ tabel $=\quad$ 1.96. Fakta ini mengungkapkan bahwa t hitung $<\mathrm{t}$ tabel, berarti $\mathrm{H} 0$ diterima dan $\mathrm{H} 1$ ditolak. Artinya koefisien jalur ini tidak signifikan.

\section{SIMPULAN}

Berdasarkan hasil analisis data dengan menggunakan aplikasi Smart PLS Versi 3, diperoleh koefisien jalur $(\gamma 1)=0.202$. Harga $t$ hitung $=$

Tabel 4 Hasil dari Inner model

\begin{tabular}{lccc}
\hline & Original Sample & & \\
& $(\mathrm{O})$ & T Statistic (O/STERR) & Keterangan \\
\hline Motivasi $\rightarrow$ Kinerja Tutor & 0.619 & 5.476 & Signifikan \\
\hline Kepuasan Kerja $\rightarrow$ Kinerja Tutor & 0.202 & 1.715 & Tidak Signifikan \\
\hline \hline e-ISSN 2685-2977 & Jurnal Ekonomika, Volume 12 Nomor 01, Januari 2021
\end{tabular}


1.715, sedangkan harga $\mathrm{t}$ tabel = 1.96. yang berarti ada pengaruh yang signifikan antara kepuasan kerja terhadap kinerja tutor. Artinya variabel kepuasan kerja berperan terhadap kinerja tutor di UPBJJ Tarakan. Seorang tutor dapat menjalankan tugasnya dikarenakan adanya kepuasan kerja yang didapatnya selama bekerja.

\section{DAFTAR PUSTAKA}

Arends, R. I. (2011). Learning to Teach. New York: McGrawHill Education.

Ase ad, M, 2003, Psikologi Industri, Edisi Keempat, Yogyakarta: Liberty.

Celluci, Anthony J, and David L. De Vries. (1978). Measuring Managerial Satisfaction: A Manual for the MJSQ, Technical Report II (Center for Creative Leadership).

Ghozali, I. (2009). Ekonometrika: Teori, Konsep dan Aplikasi dengan SPSS 17. Semarang: Badan Penerbit Universitas Diponegoro.

Handoko, H. (2008). Manajemen Personalia dan Sumber Daya Manusia. Edisi

Yogyakarta: BPFE Yogyakarta.

Mathis, R. dan Jackson, W. (2006).

Human Resources

Development. Jakarta:
Kreitner. (2005). Perilaku Organisasi. In E. Kelima. Buku 1. Jakarta: Salemba Empat.

Robert L. Mathis dan John H. Jackson. 2006. Human Resource Management, Jakarta:Selemba Empat.

Robbins, Stephen P., \& Judge, Timothy A. (2009). Perilaku Organisasi (Edisi 12). Diterjemahkan oleh Angelica, Diana, Cahyani, Ria, Rosyid dan Abdul. Jakarta: Salemba Empat.

Sugiran, Daulay, dkk .(2016). Evaluasi Tutor Online untuk Meningkatkan Kualitas, Layanan Tutorial Tatap Muka pada Pendidikan Jarak Jauh. Journal of Information Systems Engineering and Business Intelligence Vol. 2, No. 1, April 2016

Wirawan, 2009, Evaluasi Kinerja Sumber Daya Manusia, Teori, Aplikasi, dan Penelitian, Jakarta:Salemba Empat.

Yamin, M. dan Maisah, 2010, Standarisasi Kinerja Guru, Jakarta: Gaung Persada (GP Press).

Yunus, Mohamad. (2007). Dasardasar Motivasi Kerja. Jakarta: Penerbit Universitas 